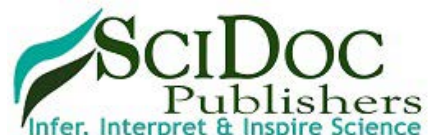

International Journal of Dentistry and Oral Science (IJDOS)

ISSN: 2377-8075

\title{
Survey of Dental Caries Among Students in Junior High School in Shiraz
}

Short Commentary

Karimi $\mathrm{M}^{*}$

Chief Dental Officer, Apple Dental Clinic, Iran.

Ninety years of modern dentistry activities has passed in Iran, but the statistics of dental health indicators in this country have not significantly improved. The most problems in the field of Dentistry in Iran including the numbers of extracted, decayed and restored teeth are very high among the Iranians. This problem in the area of oral health is due to the misconception of dentistry which has been dominated in the past. Before the people believed that their teeth cannot be used for the whole life. If the teeth have decays, they must take them out. So, they don't have any other choices except to replace them with full mouth dentures. Fortunately, this thinking, view and approach are outdated. It seems public opinion and the authorities views have changed prospective to dental and oral health; and turned toward preventive dentistry.

On behalf of Apple Dental Clinic, I started a project survey at the junior high schools in Shiraz. The majority of the students, who were examined, had dental caries. A significant numbers of them suffered from mild to moderate Gingivitis. The main factors included as poor eating habits and negligence of oral health. Dental caries and periodontal tissues inflammation due to high consumption of sweets, low levels of attention to oral health and oral hygiene, low parental understanding of the causes of decay and laziness and neglect in the care of their teeth had high prevalence.

TV commercials such as introducing different kinds of potatoes chips and snacks which their consumption causes damage to the children teeth, is another factor that leads to dental caries among the adolescents.

It should be noted that in order to prevent dental caries and accumulations of dental calculus, there is only one approved pattern: control of oral health and oral hygiene; not using soft, sticky materials and sweets; and having a daily vegetarian food pattern.

I observed the majority of these young students are not really concerned about their dental problems; or even ashamed of having bad breath. Unfortunately, these adolescent students are not aware that maintaining healthy teeth and mouth not only are not less important than other organs but also can have a negative effect on the health of other parts of their bodies; and even have a negative impact on their social life.

In recent years, the viewpoints of official at the Ministry of Health have been changed, and we are observing the positive changes. Appropriate measures such as fluoride therapy, fissure sealants, and attention to addressing the health status of students in schools have been started that is a new hope for new generation in Iran.

I believe in collaboration with dentists in a national project, we are able to reduce the damage of dental caries and dental problems among adolescent students. But this fact would happen if only the media and the educational system deliver this important massage properly.

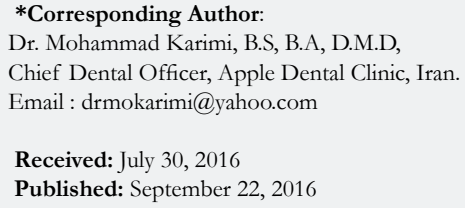

Copyright: Karimi $\mathbf{M}^{\odot}$ 2016. This is an open-access article distributed under the terms of the Creative Commons Attribution License, which permits unrestricted use, distr bution and reproduction in any medium, provided the original author and source are credited. 